\title{
Pengaruh Dukungan Sosial terhadap Kesejahteraan Psikologis Mahasiswa dengan Religiusitas sebagai Moderator
}

\author{
(The Effect of Social Support on Students' Psychological Well-being with Religiosity as a \\ Moderator)
}

\author{
Nur Eva ${ }^{1 *}$, Pravissi Shanti ${ }^{1}$, Nur Hidayah ${ }^{2}$, Moh. Bisri ${ }^{1}$ \\ ${ }^{1} J u r u s a n$ Psikologi, Fakultas Pendidikan Psikologi, Universitas Negeri Malang, \\ Jl. Semarang No. 5, Malang, Jawa Timur, 65145 Indonesia \\ ${ }^{2}$ Jurusan Bimbingan dan Konseling, Fakultas Ilmu Pendidikan, Universitas Negeri Malang, \\ Jl. Semarang No. 5, Malang, Jawa Timur, 65145 Indonesia \\ *corresponding author, e-mail: nur.eva.fppsi@um.ac.id
}

Article received: March $28^{\text {th }} 2020$; revised: June $22^{\text {nd }} 2020$; accepted: July $7^{\text {th }} 2020$

\begin{abstract}
Previous studies have indicated that psychological well-being has a positive contribution to mental health and is a predictor of academic achievement, self-control, life satisfaction, gratitude, optimism, hope, and happiness. Psychological well-being is also influenced by social support and religiosity. This study aimed to examine the effect of social support on students' psychological wellbeing, with religiosity as a moderator. This study employed a correlational research design with 354 participants recruited using a simple random sampling technique. Data were collected using a social support scale, a religious scale, and a psychological well-being scale. The data were then analyzed using moderated regression analysis. The results showed that social support contributed significantly to the psychological well-being of students, but religiosity did not increase the contribution of social support to psychological well-being. Based on these results, social support, one of which can be provided through peer counseling, is needed to improve the psychological well-being of students.
\end{abstract}

Keywords: psychological well-being; social support; religiosity

\begin{abstract}
Abstrak: Hasil-hasil penelitian terdahulu menunjukkan bahwa kesejahteraan psikologis memiliki kontribusi positif terhadap kesehatan mental dan merupakan prediktor bagi prestasi akademik, kontrol diri, kepuasan hidup, rasa syukur, optimisme, harapan, dan kebahagiaan. Kesejahteraan psikologis juga dipengaruhi oleh dukungan sosial dan religiusitas. Penelitian ini bertujuan untuk menguji pengaruh dukungan sosial terhadap kesejahteraan psikologis mahasiswa, dengan religiusitas sebagai moderator. Penelitian ini menggunakan rancangan penelitian korelasional. 354 sampel penelitian diperoleh dengan teknik simple random sampling. Pengumpulan data dilakukan dengan menggunakan skala dukungan sosial, skala religiusitas, dan skala kesejahteraan psikologis. Data kemudian dianalisis dengan moderated regression analysis. Hasil penelitian menunjukkan bahwa dukungan sosial berkontribusi signifikan terhadap kesejahteraan psikologis mahasiswa, namun religiusitas tidak meningkatkan kontribusi dukungan sosial terhadap kesejahteraan psikologis tersebut. Berdasarkan hasil tersebut, dukungan sosial, yang salah satunya dapat diberikan melalui konseling sebaya, dibutuhkan untuk meningkatkan kesejahteraan psikologis mahasiswa.
\end{abstract}

Kata kunci: kesejahteraan psikologis; dukungan sosial; religiusitas 


\section{PENDAHULUAN}

Kesejahteraan psikologis menggambarkan kondisi mental individu yang berfungsi secara positif. Nilai positif dari kondisi mental ini memberikan kontribusi signifikan terhadap kehidupan individu. Kesejahteraan psikologis menciptakan emosi positif pada individu dalam menghadapi problematika kehidupan sehingga memilih solusi yang tepat. Konstruk kesejahteraan psikologis bersifat multidimensi. Model kesejahteraan psikologis Ryff, (2014) menjelaskan bahwa terdapat enam dimensi yang menjadi tolak ukur kesejahteraan psikologis individu, yaitu: penerimaan terhadap kelebihan dan kekurangan yang dimiliki individu, mengarahkan hidup pada tujuan tertentu, menjalin hubungan yang baik dengan orang lain, mempunyai kemandirian, mampu mengendalikan lingkungan, dan mengembangkan diri dengan berkelanjutan.

Kesejahteraan psikologis merupakan kondisi mental yang penting untuk dikembangkan dalam layanan bimbingan dan konseling pada mahasiswa. Hal ini berfungsi untuk mendukung pencapaian tugas-tugas perkembangan mahasiswa pada aspek pribadi-sosial, akademis, dan karier, karena tujuan khusus dari layanan bimbingan dan konseling adalah membantu peserta didik untuk mencapai tugastugas perkembangannya pada aspek pribadi-sosial, akademis, dan karier (Wardati \& Jauhar, 2011).

Kesejahteraan psikologis penting bagi mahasiswa agar tumbuh menjadi pribadi yang produktif dalam bidang akademik dan berbagai bidang kehidupan. Kesejahteraan psikologis pada mahasiswa menjadi prediktor: prestasi akademik (Iosua et al., 2014), kontrol diri (Udhayakumar \& Illango, 2018), kepuasan hidup, rasa syukur, optimis, harapan (Kardas, Cam, Eskisu, \& Gelibolu, 2019), dan kebahagiaan (Ghasempour, Jodat, Soleimani, \& Zhalehshabanlo, 2013). Kesejahteraan psikologis menjadi prediktor berbagai aspek kehidupan mahasiswa, seperti, aspek pribadi-sosial, akademis, dan karier.

Mahasiswa adalah individu yang sedang dalam proses menjadi orang dewasa. Di Indonesia, mahasiswa berusia 18 hingga 25 tahun. Dalam kajian psikologi, mahasiswa termasuk dalam periode emerging adulthood, yang merupakan periode transisi antara remaja dan dewasa. Adapun karakterisitik yang paling menonjol pada periode emerging adulthood adalah ketidakstabilan (Syed, 2015). Hal ini disebabkan eksplorasi yang dilakukan mahasiswa pada semua bidang kehidupan membuat mahasiswa menghadapi banyak masalah seperti: masalah akademik, keuangan, romantisme, dan hubungan pertemanan. Berbagai masalah yang dihadapi mahasiswa menyebabkan munculnya masalah psikologis, seperti kecemasan, stres, dan depresi. Permasalahan psikologis ini berdampak pada penurunan kesejahteraan psikologis mahasiswa.

Fenomena rendahnya kesejahteraan psikologis pada kalangan mahasiswa ditemukan di berbagai belahan dunia (Ghasempour et al., 2013; Punia \& Malaviya, 2015). Rendahnya kesejahteraan psikologis mahasiswa juga ditemukan di Indonesia. Triaswari \& Utami, (2014) menemukan bahwa 27,26\% mahasiswa psikologi Universitas Gadjah Mada memiliki kesejahteraan psikologis yang rendah. Putri, (2012) menemukan bahwa 46,2\% mahasiswa Universitas Indonesia memiliki kesejahteraan psikologis yang rendah. Sebanyak 38\% dari mahasiswa Universitas Pendidikan Indonesia memiliki kesejahteraan psikologis yang rendah (Kurniasari, Rusmana, \& Budiman, 2019).

Rendahnya kesejahteraan psikologis mahasiswa yang sedang menempuh perkuliahan di Malang ditunjukkan dari konflik antar mahasiswa (Parela, Saffanah, \& Anwar, 2018), stres (Ambarwati, Pinilih, \& Astuti, 2019; Hamadi, Wiyono, \& Rahayu, 2018), penyesuaian diri yang rendah (Sari \& Jamain, 2019) serta penerimaan diri mahasiswa yang rendah (Prabowo, 2020). Konflik antar mahasiswa, stres, penyesuaian diri dan penerimaan diri mahasiswa yang rendah akan berdampak pada hubungan sosial, pencapaian tujuan hidup, dan pengembangan diri sehingga menyebabkan penurunan kesejahteraan psikologis mahasiswa.

Berbagai penelitian tentang kesejahteraan psikologis menunjukkan bahwa kesejahteraan psikologis dipengaruhi oleh kepribadian (Hicks \& Mehta, 2018), religiusitas (Harpan, 2015), status sosial (Fassbender \& Leyendecker, 2018), dan dukungan sosial (Adyani, Suzanna, Safuwan, \& Muryali, 2018). Terutama bagi mahasiswa, dukungan sosial merupakan faktor yang penting bagi kesejahteraan psikologis mahasiswa (Z. Luo, Wu, Fang, \& Brunsting, 2019). Dukungan sosial tersebut akan membuat mahasiswa tetap sehat secara fisik dan mental (Yasin \& Dzulkifli, 2010).

Korelasi positif antara kesejahteraan psikologis dan dukungan sosial pada mahasiswa telah ditemukan dalam berbagai penelitian (Adyani et al., 2018; Triaswari \& Utami, 2014; Yasin \& Dzulkifli, 2010). Kesejahteraan psikologis mahasiswa mengalami peningkatan seiring dengan diterimanya 
dukungan sosial. Bantuan yang diterima mahasiswa, berupa materi, penghargaan, dan perhatian akan membantu mahasiswa menghadapi situasi yang tidak menyenangkan dan meningkatkan kemampuan mahasiswa beradaptasi dengan lebih baik.

Dalam kajian hubungan antara dukungan sosial dan kesejahteraan psikologis, terdapat faktor religiusitas yang berfungsi memperkuat hubungan antara dukungan sosial dan kesejahteraan psikologis. Artinya, individu yang menerima dukungan sosial akan mempunyai kesejahteraan psikologis yang lebih baik jika mempunyai religiusitas yang baik. Kesejahteraan psikologis adalah salah satu indikator kesehatan mental. Dalam kajian kesehatan mental dikenal Teori Iceberg Model of Health and Illness (Travis \& Ryan, 2004). Teori tersebut menjelaskan bahwa kesehatan mental dipengaruhi oleh perilaku individu dan perilaku individu didasari oleh spiritualitas. Salah satu ekspresi spritualitas adalah religiusitas. Teori ini dapat menjelaskan bagaimana hubungan dukungan sosial dengan kesejahteraan psikologis yang diperkuat oleh religiusitas.

Worthington et al., (2003) menjelaskan bahwa religiusitas adalah seberapa dalam individu meyakini nilai-nilai agama, kepercayaan, dan praktiknya, serta melaksanakan ajaran agama dalam kehidupan. Berdasarkan definisi tersebut, dapat dipahami bahwa individu yang religius akan menilai kehidupan berdasarkan ajaran agama dan menyatukan agama dalam berbagai aktivitas. Religiusitas akan tampak pada perilaku mentaati nilai-nilai agama, kepercayaan, dan praktik serta menggunakannya dalam kehidupan sehari-hari, termasuk menjadi landasan menerima dukungan sosial. Religiusitas mempunyai dua dimensi, yaitu intrapersonal dan interpersonal. Dimensi intrapersonal bersumber dari nilai-nilai agama dan kepercayaan. Dimensi interpersonal bersumber dari keterlibatan individu dengan komunitas atau organisasi keagamaan, termasuk juga memberi dan menerima dukungan sosial.

Berdasarkan penjelasan pada paragraf sebelumnya, pemberian dukungan sosial akan meningkatkan kesejahteraan psikologis jika diperkuat oleh religiusitas. Sebaliknya, jika religiusitas menurun maka peningkatan pemberian dukungan sosial tidak berpengaruh terhadap kesejahteraan psikologis. Hal ini menunjukkan bahwa pengaruh dukungan sosial terhadap kesejahteraan psikologis mahasiswa dimoderatori oleh religiusitas.

Penelitian hubungan dukungan sosial terhadap kesejahteraan psikologis mahasiswa telah banyak dilakukan (Adyani et al., 2018; Pertiwi \& Utami, 2018; Yasin \& Dzulkifli, 2010). Namun, penelitian yang menjelaskan bahwa pengaruh dukungan sosial terhadap kesejahteraan psikologis mahasiswa dengan religiusitas sebagai moderator belum banyak dilaporkan. Religiusitas menjadi variabel yang berkontribusi luas dalam kehidupan masyarakat Indonesia, termasuk berpengaruh terhadap hubungan dukungan sosial dan kesejahteraan psikologis. Travis \& Ryan, (2004) menjelaskan bahwa religiusitas merupakan sumber kesehatan mental.

Selain itu, mahasiswa saat ini merupakan generasi Z, yaitu generasi yang mempunyai karakteristik berbeda dengan generasi sebelumnya, terutama terkait dengan penggunaan internet. Mereka disebut generasi internet (internet generation). Keistimewaan dari karakteristik generasi $\mathrm{Z}$ yaitu generasi yang lebih menyukai kegiatan sosial dibandingkan generasi sebelumnya (Kupperschmidt, 2000). Fenomena ini menunjukkan mereka secara emosi lebih mudah teraktivasi untuk memberikan dukungan sosial kepada anggota masyarakat, selanjutnya hal ini akan meningkatkan kesejahteraan psikologis anggota masyarakat, termasuk mahasiswa. Bersumber dari manakah motivasi generasi $\mathrm{Z}$ melakukan kegiatan sosial ini? Untuk menjawab pertanyaan tersebut penulis ingin meneliti bahwa variabel religiusitas yang mengakar dalam masyarakat Indonesia akan memberikan pengaruh dukungan sosial terhadap kesejahteraan psikologis. Berdasarkan hal itu, tujuan penelitian ini adalah untuk mengetahui pengaruh dukungan sosial terhadap kesejahteraan psikologis mahasiswa dengan religiusitas sebagai moderator.

\section{METODE}

Metode kuantitatif dengan rancangan korelasional digunakan pada penelitian ini. Tujuan penelitian ini adalah menguji pengaruh dukungan sosial terhadap kesejahteraan psikologis mahasiswa dengan religiusitas sebagai moderator. Terdapat tiga variabel yang digunakan pada penelitian, yaitu: dukungan sosial sebagai variabel prediktor, kesejahteraan psikologis sebagai variabel outcome, dan religiusitas sebagai variabel moderator. Hubungan antar variabel disajikan pada Gambar 1. 


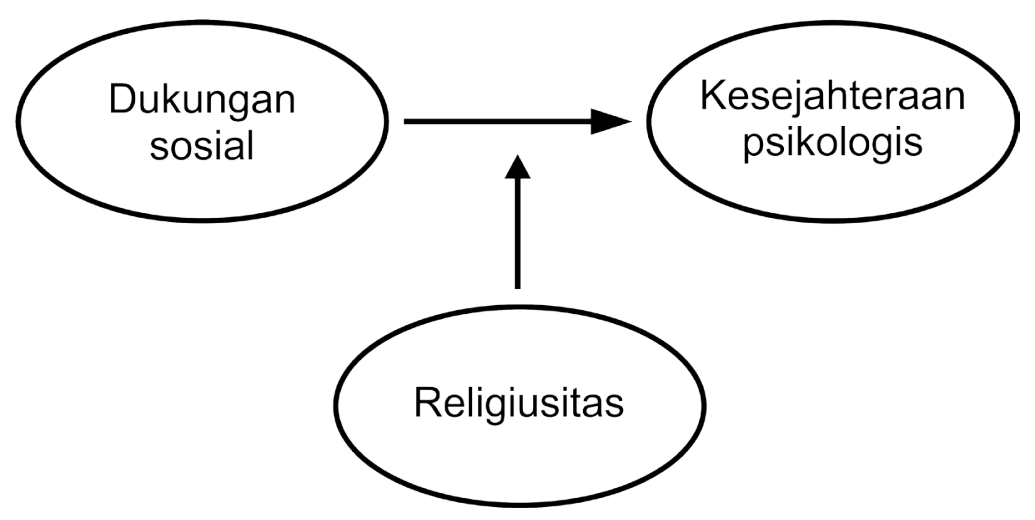

Gambar 1. Model dari Pengaruh Dukungan Sosial terhadap Kesejahteraan Psikologis Mahasiswa dengan Religiusitas sebagai Moderator

Populasi penelitian ini adalah mahasiswa Fakultas Pendidikan Psikologi Universitas Negeri Malang angkatan 2015-2018 berjumlah 735 mahasiswa dan berusia 18-25 tahun. Teknik sampling yang digunakan adalah simple random sampling dimana untuk memperoleh sampel dilakukan dengan memilih nomor ganjil dari daftar nama mahasiswa angkatan 2015-2018. Total sampel dari nomor ganjil berjumlah 368 mahasiswa. Mereka diminta mengisi skala penelitian melalui Google Form yang dikirim melalui personal chat, namun yang merespon sebanyak 354 mahasiswa.

Data dalam penelitian ini diambil dengan menggunakan skala adaptasi. Ada tiga skala yang digunakan yaitu: skala kesejahteraan psikologis, skala dukungan sosial, dan skala religiusitas. Skala kesejahteraan psikologis diadaptasi dari Psychological Well-being Scale (Ryff \& Singer, 2006). Skala ini mempunyai enam dimensi, yaitu: penerimaan diri (self-acceptance), pertumbuhan pribadi (personal growth), tujuan hidup (life goal), penguasaan lingkungan (environmental mastery), kemandirian (independence) and hubungan dengan orang lain (positive relationships with others). Skala ini disusun berdasarkan skala Likert. Terdiri dari 42 butir pernyataan. Koefisien reliabitilas skala sebesar 0,856 dan validitas sebesar $0,306-0,723$

Skala dukungan sosial diadaptasi dari Scale of Perceived Social Support (Zimet, Dahlem, Zimet, \& Farley, 1988). Skala ini mempunyai tiga dimensi yaitu: keluarga (family), teman (friend), dan orang lain yang berpengaruh (other people who have a significant effect). Skala ini disusun berdasarkan skala Likert. Terdiri dari dua belas butir pernyataan. Koefisien reliabilitas skala sebesar 0,912 dan validitas sebesar $0,572-0,754$.

Skala religiusitas diadaptasi dari Religious Commitment Inventory-10 (RCI-10) (Worthington et al., 2003). Skala ini mempunyai dua dimensi, yaitu: intrapersonal dan interpersonal. Skala ini disusun berdasarkan skala Likert. Terdiri dari sepuluh butir pernyataan. Koefisien reliabilitas skala sebesar 0,884 dan validitas sebesar $0,501-0,735$.

Pengumpulan data dilakukan dengan menggunakan Google Form karena penelitian dilakukan pada bulan Juli-Agustus 2019 ketika mahasiswa libur. Data yang terkumpul dianalisis dengan moderated regression analysis dengan tujuan untuk mengetahui pengaruh dukungan sosial terhadap kesejahteraan psikologis mahasiswa dengan religiusitas sebagai moderator.

\section{HASIL}

Untuk mengetahui tingkat dukungan sosial, religiusitas, dan kesejahteraan psikologis mahasiswa dapat diketahui dari data deskriptif pada tabel 1. Pada tabel 1, DS adalah dukungan sosial, RE adalah religiusitas, $\mathrm{KP}$ adalah kesejahteraan psikologis.

Tabel 1. Data Deskriptif Dukungan Sosial, Religiusitas, dan Kesejahteraan Psikologis Mahasiswa

\begin{tabular}{ccccc}
\hline Variabel & Mean Empiris & Standar Deviasi Empiris & Mean Hipotetik & Standar Deviasi Hipotetik \\
\hline DS & 54,31 & 10,973 & 21 & 10 \\
RE & 36,599 & 7,554 & 30 & 6,67 \\
KP & 170,364 & 19,725 & 147 & 35 \\
\hline
\end{tabular}


Berdasarkan data deskriptif diketahui bahwa dukungan sosial, religiusitas, dan kesejahteraan psikologis mempunyai mean empiris lebih tinggi daripada mean hipotetik. Hal ini berarti realitas tingkat dukungan sosial, religiusitas, dan kesejahteraan psikologis mahasiswa lebih baik dibandingkan tingkat dukungan sosial, religiusitas, dan kesejahteraan psikologis yang diprediksi oleh skala. Secara lebih detail, data deskriptif disajikan pada tabel 2, tabel 3, dan tabel 4.

Pada Tabel 2 dan 3 diketahui bahwa sebagian besar tingkat dukungan sosial (95,6\%) dan religiusitas mahasiswa (54\%) dalam kategori tinggi. Sedangkan pada tabel 4, diketahui bahwa sebagian besar tingkat kesejahteraan psikologis mahasiswa dalam kategori sedang $(73,4 \%)$.

Pengujian hipotesis untuk membuktikan pengaruh dukungan sosial terhadap kesejahteraan psikologis mahasiswa dengan religiusitas sebagai moderator dilakukan dengan moderated regression analysis. Pada dasarnya analisis dengan moderated regression analysis merupakan analisis regresi sehingga sebelum menguji hipotesis akan dilakukan uji asumsi terlebih dahulu. Uji asumsi untuk analisis regresi meliputi uji normalitas, heteroskedastisitas, dan linieritas.

Uji asumsi yang pertama adalah uji normalitas dengan menggunakan Kolmogorov Smirnov yang bertujuan untuk menguji apakah data yang digunakan dalam penelitian berdistribusi normal atau tidak. Hasil uji normalitas Kolmogorov Smirnov disajikan pada Tabel 5. Berdasarkan hasil uji normalitas yang dijabarkan pada Tabel 5, diketahui bahwa nilai signifikansi asymp. sig. (2-tailed) sebesar 0,177 lebih besar dari 0,05. Sesuai dengan dasar pengambilan keputusan dalam uji normalitas Kolmogorov Smirnov, diketahui bahwa data kesejahteraan psikologis berdistribusi normal. Dengan demikian, asumsi atau persyaratan normalitas dalam model regresi terpenuhi.

Uji asumsi yang kedua adalah uji heteroskedastisitas. Uji heteroskedastisitas dengan uji Glejser bertujuan untuk menilai apakah ada ketidaksamaan varian dari residual untuk semua pengamatan pada model regresi. Hasil uji heteroskedastisitas ditampilkan pada Tabel 6.

Berdasarkan hasil uji heteroskedastisitas yang dijabarkan pada tabel 6, diketahui bahwa nilai signifikansi lebih besar dari 0,05 . Sesuai dengan dasar pengambilan keputusan dalam uji heteroskedastisitas, diketahui bahwa tidak ditemukan gejala adanya heteroskedastisitas karena ketiga variabel signifikansinya lebih dari 0,05 . Dengan demikian, asumsi atau persyaratan heteroskedastisitas pada variabel dukungan sosial, religiusitas, dan kesejahteraan psikologis dalam model regresi terpenuhi.

Uji asumsi yang ketiga adalah uji linieritas. Uji linieritas bertujuan untuk mengetahui apakah dua variabel atau lebih memiliki hubungan linier secara signifikan atau tidak. Hasil uji linieritas ditampilkan pada Tabel 7. Hasil yang diperhatikan, yaitu kolom F-linearity. F-linearity menunjukkan sejauh mana jika variabel dependen diprediksi berbaring persis di garis lurus. Jika hasilnya signifikan $(\mathrm{p}<0,05)$ maka model linier cocok diterapkan pada hubungan model tersebut. Berdasarkan hasil uji linieritas yang dijabarkan pada Tabel 7, diketahui bahwa kolom $F$-linearity mempunyai nilai signifikansi sebesar $0,000(\mathrm{p}<0,05)$. Sesuai dengan dasar pengambilan keputusan dalam uji linieritas, diketahui bahwa ada hubungan linier yang signifikan antara variabel dukungan sosial dan kesejahteraan psikologis. Dengan demikian, asumsi atau persyaratan linieritas pada variabel dukungan sosial dan kesejahteraan psikologis dalam model regresi terpenuhi.

Berdasarkan uji asumsi sebagai syarat dilakukan analisis regresi, syarat dilakukannya uji regresi telah terpenuhi. Hasil penghitungan uji korelasi ditampilkan terlebih dahulu pada Tabel 8 dan hasil perhitungan pada tabel regresi ditampilkan pada Tabel 9. Hasil korelasi antara dukungan sosial, religiusitas, dan kesejahteraan psikologis menunjukkan adanya korelasi yang positif dan sangat signifikan. Korelasi kesejahteraan psikologis dan dukungan sosial sebesar $0,542(\mathrm{p}<0,01)$ lebih tinggi dibandingkan dengan hubungan kesejahteraan psikologis dan religiusitas sebesar $0,363(p<0,01)$ dan hubungan dukungan sosial dan religiusitas sebesar $0,339(\mathrm{p}<0,001)$. Hal ini menunjukan hubungan yang paling kuat pada dukungan sosial dan kesejahteraan psikologis. Hasil korelasi antara dukungan sosial, religiusitas, dan kesejahteraan psikologis dapat dilihat pada Tabel 8. Pada tabel 8 , ${ }^{*} \mathrm{p}<0,01$, KS adalah kesejahteraan psikologis, DS adalah dukungan sosial, dan RE adalah religiusitas.

Hasil regresi pengaruh dukungan sosial dan religiusitas terhadap kesejahteraan psikologis menunjukkan bahwa pengaruh dukungan sosial dan religiusitas berkontribusi sangat signifikan terhadap kesejahteraan psikologis. Pengaruh dukungan sosial lebih besar dibandingkan religiusitas terhadap kesejahteraan psikologis. Hal ini dapat diketahui dari besarnya beta dari dukungan sosial $(0,474$; $\mathrm{p}<0,01)$ yang lebih besar dari pada beta dari religiusitas $(0,202 ; \mathrm{p}<0,01)$. Hasil regresi dari pengaruh 
Tabel 2. Hasil Kategorisasi Dukungan Sosial Berdasarkan Statistik Hipotetik

\begin{tabular}{ccc}
\hline Kategorisasi & Frekuensi & Persentase \\
\hline Tinggi & 342 & 95,6 \\
Sedang & 12 & 3,4 \\
Rendah & 0 & 0 \\
\hline
\end{tabular}

Tabel 3. Hasil Kategorisasi Religiusitas Berdasarkan Statistik Hipotetik

\begin{tabular}{ccc}
\hline Kategorisasi & Frekuensi & Persentase \\
\hline Tinggi & 191 & 54,0 \\
Sedang & 142 & 40,1 \\
Rendah & 21 & 5,9 \\
\hline
\end{tabular}

Tabel 4. Hasil Kategorisasi Kesejahteraan Psikologis Berdasarkan Statistik Hipotetik

\begin{tabular}{ccc}
\hline Kategorisasi & Frekuensi & Persentase \\
\hline Tinggi & 93 & 26,3 \\
Sedang & 260 & 73,4 \\
Rendah & 1 & 0,3 \\
\hline
\end{tabular}

Tabel 5. Hasil Uji Normalitas Kesejahteraan Psikologis

\begin{tabular}{cc}
\hline N & 354 \\
Mean & 170,364 \\
SD & 19,725 \\
Asymp. Sig. (2-tailed) & 0,177 \\
\hline
\end{tabular}

Tabel 6. Hasil Uji Heteroskedastisitas Variabel Dukungan Sosial dan Religiusitas

\begin{tabular}{ccc}
\hline Variabel & t & Signifikansi \\
\hline $\mathrm{DS}$ & $-0,976$ & 0,330 \\
$\mathrm{RE}$ & 1,169 & 0,243 \\
\hline
\end{tabular}

Tabel 7. Hasil Uji Linieritas Dukungan Sosial dan Kesejahteraan Psikologis

\begin{tabular}{ccc}
\hline & F-linearity & Signifikansi \\
\hline DS dan KP & 155,747 & 0,000 \\
\hline
\end{tabular}

Tabel 8. Hasil Korelasi Antara Dukungan Sosial, Kesejahteraan Psikologis, dan Religiusitas

\begin{tabular}{cccc}
\hline & KS & DS & RE \\
\hline KS & 1,000 & $0,542^{*}$ & $0,363^{*}$ \\
DS & $0,542^{*}$ & 1,000 & $0,339^{*}$ \\
RE & $0,363^{*}$ & $0,339^{*}$ & 1,000 \\
\hline
\end{tabular}

Tabel 9. Hasil Regresi Dukungan Sosial, Religiusitas, dan Kesejahteraan Psikologis

\begin{tabular}{ccccc}
\hline Model & B & Beta & t & Sig. \\
\hline 1 (Constant) & 104,782 & & 20,040 & 0,000 \\
DS & 0,851 & 0,474 & 10,200 & 0,000 \\
RE & 0,528 & 0,202 & 4,357 & 0,000 \\
\hline
\end{tabular}


Tabel 10. Analisis Moderated Regression dari Pengaruh Dukungan Sosial terhadap Kesejahteraan Psikologis Mahasiswa dengan Religiusitas sebagai Moderator

\begin{tabular}{cccccc}
\hline & $\mathbf{R}^{2}$-chng & F & df1 & df2 & p \\
\hline DS*RE & 0,0001 & 0,0404 & 1,0000 & 350,000 & 0,8409 \\
\hline
\end{tabular}

dukungan sosial terhadap kesejahteraan psikologis dan religiusitas terhadap kesejahteraan psikologis dapat dilihat pada Tabel 9. Pada tabel 9, Variabel outcame adalah kesejahteraan psikologis, Prediktor adalah dukungan sosial dan religiusitas.

Berdasarkan hasil moderated regression analysis diketahui bahwa pengaruh dukungan sosial terhadap kesejahteraan psikologis mahasiswa dengan religiusitas sebagai moderator tidak berbukti. Dengan kata lain, religiusitas tidak berfungsi sebagai moderator $(\mathrm{p}=0,8409 ; \mathrm{p}>0,05)$ pada pengaruh dukungan sosial terhadap kesejahteraan psikologis. Hasil uji moderated regression analysis dapat dilihat pada Tabel 10. Pada tabel 10, prediktor adalah DS, dan moderator adalah RE.

\section{PEMBAHASAN}

Dukungan sosial berpengaruh terhadap kesejahteraan psikologis namun religiusitas bukan faktor yang memperkuat pengaruh dukungan sosial terhadap kesejahteraan psikologis. Artinya terdapat faktor lain yang mungkin berpengaruh terhadap hubungan dukungan sosial dan kesejahteraan psikologis, yaitu budaya kolektif pada masyarakat Indonesia. Ini mendukung gagasan Cross, (2003) yang menyatakan bahwa budaya dapat menjadi sumber daya positif untuk kesehatan mental individu. Masyarakat Indonesia mempunyai budaya kolektif yang tercermin dalam budaya gotong royong. Ekspresi budaya gotong royong termasuk memberikan dukungan sosial terhadap anggota masyarakat yang sedang menghadapi permasalahan. Pengaruh dukungan sosial terhadap kesejahteraan psikologis mahasiswa tidak lepas dari budaya kolektif yang mengakar pada masyarakat Indonesia. Hasil penelitian ini meneguhkan kembali bahwa dukungan sosial dibutuhkan mahasiswa untuk meningkatkan kesejahteraan psikologis. Sebagaimana penelitian-penelitian sebelumnya bahwa dukungan sosial merupakan prediktor kesejahteraan psikologis individu. Ketika individu mendapatkan dukungan sosial maka kesejahteraan psikologisnya akan meningkat (Adyani et al., 2018; Pertiwi \& Utami, 2018; Yasin \& Dzulkifli, 2010).

Mahasiswa sebagai individu dalam periode emerging adulthood, yaitu transisi dari remaja menuju dewasa, menghadapi banyak problematika, seperti percintaan, akademik, dan keuangan. Pada periode ini, kehidupan mahasiswa penuh stres. Hal ini menyebabkan kehidupan mahasiswa penuh dengan ketidakstabilan. Syed, (2015) menyebutnya sebagai the age of instability, dimana terjadi banyak perubahan dalam kehidupan mahasiswa, seperti perubahan hubungan dengan orang lain, perubahan tempat tinggal, dan perubahan pekerjaan. Pada periode ini, perubahan terjadi lebih sering dibandingkan pada periode sebelum dan sesudahnya.

Kehidupan yang penuh stres dan ketidakstabilan ini berdampak pada kesejahteraan psikologis mahasiswa (Aulia \& Panjaitan, 2019) yang mengalami penurunan kesejahteraan psikologis. Hal ini tampak pada fenomena mahasiswa yang tidak mempunyai tujuan hidup, relasi sosialnya memburuk, kemandiriannya menurun, kontrol terhadap lingkungannya melemah, tidak melakukan pengembangan potensi yang dimiliki, serta menolak kelemahan dan kelebihan yang ada pada dirinya.

Kesejahteraan psikologis mahasiswa dapat diperbaiki dengan meningkatkan dukungan sosial. Konsep pemberian dukungan sosial dikembangkan untuk mengatasi stres yang dirasakan oleh individu. Mahasiswa yang sedang mengalami stres akan menjadi sehat kembali secara mental dan psikologis jika menerima dukungan sosial, selanjutnya kesejahteraan psikologisnya juga akan meningkat. Beberapa penelitian menunjukkan bahwa kesejahteraan psikologis mahasiswa berkorelasi positif dengan dukungan sosial yang diterimanya (Adyani et al., 2018; Z. Luo et al., 2019; Yasin \& Dzulkifli, 2010). Terdapat beberapa fungsi dukungan sosial pada mahasiswa, seperti: membantu mahasiswa menghadapi situasi yang tidak menyenangkan, meningkatkan kemampuan penyesuaian diri, dan menjadi penopang ketika mahasiswa menghadapi menghadapi masalah. Dengan demikian, dukungan sosial menyediakan sumber untuk meningkatkan kesejahteraan psikologis mahasiswa. 
Cohen, (2004) menjelaskan bahwa dukungan sosial berfungsi untuk mencegah kecemasan, meningkatkan harga diri, mencegah gangguan psikologis, dan mengurangi stres pada diri individu. Kesejahteraan psikologis dapat ditingkatkan dengan memberikan dukungan sosial berupa pemberian semangat dan perhatian pada individu yang sedang menghadapi masalah. Dapat diketahui bahwa terdapat hubungan positif dukungan sosial dan kesejahteraan psikologis. Dukungan sosial dapat diperoleh mahasiswa dari keluarga, teman, dan orang lain yang berpengaruh terhadap mahasiswa, seperti, dosen, kekasih, atau orang di lingkungannya. Dukungan keluarga menyediakan sumber daya instrumental dan psikologis. Mahasiswa yang tinggal terpisah dengan keluarga tetap mendapatkan dukungan sosial berupa keuangan dan motivasi. Dukungan sosial dari teman menjadi kebutuhan yang lebih besar dibandingkan dukungan keluarga karena mahasiswa lebih banyak berinteraksi dengan teman dibandingkan keluarga. Hampir seluruh waktu belajar, bermain, dan tinggal dihabiskan bersama teman selama masa perkuliahan. Mahasiswa memperoleh dukungan psikologis, instrumental, dan informasi dari teman.

Selain dari keluarga dan teman, mahasiswa juga mendapat dukungan sosial dari orang lain yang berpengaruh, seperti, dosen, pasangan, atau orang di lingkungan. Pada masa perkuliahan, mahasiswa juga berinteraksi dengan dosen. Mahasiswa mendapatkan dukungan sosial dari dosen berupa berbagai informasi tentang perkuliahan dan pemecahan masalah yang dihadapi mahasiswa pada saat masa perkuliahan, baik terkait dengan keuangan, akademik, psikologis, dan sosial. Demikian juga keberadaan pasangan dan orang yang di sekitar lingkungan dapat menjadi sumber dukungan sosial bagi mahasiswa.

Dukungan sosial dari Perguruan Tinggi (PT) termasuk adanya layanan bimbingan dan konseling, yang dilaksanakan oleh dosen konselor. Sebagaimana ditemukan oleh Nastiti \& Habibah, (2016) bahwa mahasiswa menggunakan layanan bimbingan dan konseling di kampus untuk mengatasi masalah yang tidak dapat diselesaikan sendiri. Layanan bimbingan dan konseling di PT membantu mahasiswa menyelesaikan tugas perkembangannya pada aspek pribadi-sosial sehingga mahasiswa menjadi lebih sejahtera secara psikologis. Dampak peningkatan kesejahteraan psikologis mahasiswa akan memperbaiki prestasi akademik dan pengembangan karier mahasiswa. Tampak bahwa layanan bimbingan dan konseling di PT mempunyai peranan yang strategis dalam meningkatkan kesejahteraan psikologis mahasiswa.

Dukungan sosial yang diterima oleh mahasiswa membantu mahasiswa menyelesaikan berbagai problematika yang ditemui selama masa transisi dari masa remaja menjadi manusia dewasa. Dukungan sosial menyebabkan penurunan tingkat stres yang dihadapi mahasiswa sehingga lebih sehat secara mental dan fisik (Astuti \& Hartati, 2013; Cohen, 2004; Y. Luo \& Wang, 2009). Kondisi mental dan fisik yang sehat akan menyebabkan peningkatan kesejahteraan psikologis. Mahasiswa akan lebih fokus pada pengembangan diri, tujuan hidupnya lebih terarah, relasi sosialnya lebih positif, lebih mampu mengontrol lingkungan, lebih mampu menerima dirinya, dan lebih mandiri. Hal ini dapat mengantarkan mahasiswa menjadi lebih sejahtera secara psikologis.

Layanan bimbingan dan konseling untuk mahasiswa dapat memanfaatkan dukungan sosial, terutama dari teman sebaya untuk meningkatkan kesejahteraan mahasiswa. Layanan bimbingan dan konseling dapat mengembangkan program konseling teman sebaya pada mahasiswa untuk membantu mahasiswa yang sedang bermasalah. Noviza, (2011) memprediksi bahwa dengan mengoptimalkan konseling teman sebaya, akan membantu mahasiswa mengatasi berbagai permasalahan yang dihadapi selama masa perkuliahan.

Hasil penelitian ini menunjukkan bahwa religiusitas bukan menjadi faktor yang memperkuat hubungan antara dukungan sosial dengan kesejahteraan psikologis, sekalipun tingkat religiusitas sebagian besar mahasiswa dalam kategori tinggi. Pada hakikatnya, tingkat religiusitas yang tinggi menunjukkan mahasiswa mengimplementasikan ajaran agama dalam kehidupan intrapersonal dan interpersonalnya. Hal ini disebabkan oleh faktor yang lain, yaitu budaya dalam masyarakat. Budaya kolektif yang mengakar dalam masyarakat Indonesia memengaruhi hubungan dukungan sosial dengan kesejahteraan psikologis mahasiswa. Cross, (2003) menjelaskan bahwa budaya dalam suatu masyarakat berpengaruh terhadap kesehatan mental individu.

Dukungan sosial juga dipengaruhi oleh budaya masyarakat (Glazer, 2006; Goodwin \& Giles, 2003). Budaya memengaruhi bagaimana individu menerima, memberi, dan mempersepsi jenis dan sumber dukungan. Masyarakat Indonesia mempunyai budaya kolektivisme akan memengaruhi dukungan sosial 
yang diterima oleh individu. Hofstede, (2011) menerangkan bahwa individu yang hidup dalam budaya kolektif akan mengintegrasikan diri dalam kelompok selama hidupnya, sejak lahir sampai akhir hayat. Kelompok akan melindungi satu sama lain sebagai satu keluarga besar. Budaya kolektif ini menjadi identitas bangsa Indonesia dan menyebabkan individu lebih mementingkan kebutuhan kelompok daripada dirinya sendiri.

Fenomena ini dapat digunakan untuk menjelaskan bahwa pemberian dukungan sosial pada anggota masyarakat adalah bukti adanya kebutuhan untuk melindungi anggota masyarakat. Artinya, jika mahasiswa sedang mengalami problematika maka ia sebagai anggota masyarakat akan mendapatkan dukungan sosial dari lingkungan karena adanya budaya kolektif dalam masyarakat Indonesia. Dukungan sosial yang diterima oleh mahasiswa, sebagai bagian masyarakat dengan budaya kolektif, akan meningkatkan kesejahteraan psikologisnya.

\section{SIMPULAN}

Pengaruh dukungan sosial terhadap kesejahteraan psikologis mahasiswa tidak dimoderatori oleh religiusitas. Dukungan sosial dibutuhkan untuk memperkuat kesejahteraan psikologis mahasiswa. Hal ini mendukung teori sebelumnya yang menjelaskan bahwa dukungan sosial adalah prediktor kesejahteraan psikologis. Pengaruh dukungan sosial terhadap kesejahteraan psikologis mahasiswa di Indonesia diperkuat oleh budaya kolektif yang berkembang di masyarakat. Penelitian ini mempertegas bahwa dukungan sosial berkontribusi terhadap peningkatan kesejahteraan mahasiswa. Layanan bimbingan dan konseling dapat menggunakan konseling teman sebaya dari sesama mahasiswa untuk membantu menyelesaikan permasalahan akademik, pribadi-sosial, dan karier mahasiswa.

\section{DAFTAR RUJUKAN}

Adyani, L., Suzanna, E., Safuwan, S., \& Muryali, M. (2018). Perceived social support and psychological wellbeing among interstate students at Malikussaleh University. Indigenous: Jurnal Ilmiah Psikologi, 3(2), 98104. https://doi.org/10.23917/indigenous.v3i2.6591

Ambarwati, P. D., Pinilih, S. S., \& Astuti, R. T. (2019). Gambaran tingkat stres mahasiswa. Jurnal Keperawatan Jiwa, 5(1), 40-47.

Astuti, T. P., \& Hartati, S. (2013). Dukungan sosial pada mahasiswa yang sedang menyusun skripsi (studi fenomenologis pada mahasiswa Fakultas Psikologi UNDIP). Jurnal Psikologi, 12(1), 1-13.

Aulia, S., \& Panjaitan, R. U. (2019). Kesejahteraan psikologis dan tingkat stres pada mahasiswa tingkat akhir. Jurnal Keperawatan Jiwa, 7(2), 127-134.

Cohen, S. (2004). Social relationships and health. American Psychologist, 59(8), 676-684. https://doi. org/10.1037/0003-066X.59.8.676

Cross, T. L. (2003). Culture as a resource for mental health. Cultural Diversity and Ethnic Minority Psychology, 9(4), 354-359.

Fassbender, I., \& Leyendecker, B. (2018). Socio-economic status and psychological well-being in a sample of Turkish immigrant mothers in Germany. Frontiers in Psychology, 9, 1586.

Ghasempour, A., Jodat, H., Soleimani, M., \& Zhalehshabanlo, K. (2013). Happiness as a predictor of psychological well-being of male athlete students. Annals of Applied Sport Science, 1(2), 25-32.

Glazer, S. (2006). Social support across cultures. International Journal of Intercultural Relations, 30(5), 605-622.

Goodwin, R., \& Giles, S. (2003). Social support provision and cultural values in Indonesia and Britain. Journal of Cross-Cultural Psychology, 34(2), 240-245.

Hamadi, H., Wiyono, J., \& Rahayu, W. (2018). Perbedaan tingkat stress pada mahasiswa yang bekerja dan tidak bekerja di Universitas Tribhuwana Tunggadewi Malang fakultas ekonomi jurusan manajemen angkatan 2013. Nursing News: Jurnal Ilmiah Keperawatan, 3(1), 369-378.

Harpan, A. (2015). Peran religiusitas dan optimisme terhadap kesejahteraan psikologis pada remaja. Empathy, $3(1), 1-18$.

Hicks, R. E., \& Mehta, Y. P. (2018). Big five, type a personality, and psychological well-being. International Journal of Psychological Studies, 10(1), 49-58.

Hofstede, G. (2011). Dimensionalizing cultures: The Hofstede model in context. Online Readings in Psychology and Culture, 2(1), 8. 
Iosua, E. E., Gray, A. R., McGee, R., Landhuis, C. E., Keane, R., \& Hancox, R. J. (2014). Employment among schoolchildren and its associations with adult substance use, psychological well-being, and academic achievement. Journal of Adolescent Health, 55(4), 542-548.

Kardas, F., Cam, Z., Eskisu, M., \& Gelibolu, S. (2019). Gratitude, hope, optimism and life satisfaction as predictors of psychological well-being. Eurasian Journal of Educational Research, 82, 81-99.

Kupperschmidt, B. R. (2000). Multigeneration employees: Strategies for effective management. The Health Care Manager, 19(1), 65-76.

Kurniasari, E., Rusmana, N., \& Budiman, N. (2019). Gambaran umum kesejahteraan psikologis mahasiswa. Journal of Innovative Counseling: Theory, Practice, and Research, 3(2), 52-58.

Luo, Y., \& Wang, H. (2009). Correlation research on psychological health impact on nursing students against stress, coping way and social support. Nurse Education Today, 29(1), 5-8.

Luo, Z., Wu, S., Fang, X., \& Brunsting, N. (2019). International students' perceived language competence, domestic student support, and psychological well-being at a U.S. university. Journal of International Students, 9(4), 954-971. https://doi.org/10.32674/jis.v0i0.605

Nastiti, D., \& Habibah, N. (2016). Studi eksplorasi tentang pentingnya layanan bimbingan konseling bagi mahasiswa di UMSIDA. Psikologia: Jurnal Psikologi, 1(1), 52-78. https://doi.org/10.21070/psikologia. v1i1.748

Noviza, N. (2011). Konseling teman sebaya (peer counseling) suatu inovasi layanan bimbingan konseling di perguruan tinggi. Wardah, 12(1), 83-98.

Parela, K. A., Saffanah, W. M., \& Anwar, K. (2018). Konflik mahasiswa timur di Kota Malang (Studi kasus pada mahasiswa timur di Kota Malang). Sosioglobal: Jurnal Pemikiran dan Penelitian Sosiologi, 3(1), 27-39.

Pertiwi, A. R. P., \& Utami, M. S. (2018). Hubungan antara dukungan sosial teman sebaya dan psychological wellbeing pada mahasiswa berorganisasi. Universitas Gadjah Mada.

Prabowo, A. H. (2020). Hubungan antara penerimaan diri dengan kecenderungan body dysmorphic disorder pada mahasiswa di Universitas Negeri Malang. Universitas Negeri Malang. Program Studi Psikologi.

Punia, N., \& Malaviya, R. (2015). Psychological well-being of first year college students. Indian Journal of Educational Studies: An Interdisciplinary Journal, 2(1), 60-68.

Putri, F. O. (2012). Hubungan antara gratitude dan psychological wellbeing pada mahasiswa. Universitas Indonesia: Depok.

Ryff, C. D. (2014). Psychological well-being revisited: Advances in the science and practice of eudaimonia. Psychotherapy and Psychosomatics, 83(1), 10-28.

Ryff, C. D., \& Singer, B. H. (2006). Best news yet on the six-factor model of well-being. Social Science Research, $35(4), 1103-1119$.

Sari, N. P., \& Jamain, R. R. (2019). Pengaruh kecerdasan dan minat pribadi sosial terhadap penyesuaian diri mahasiswa bimbingan dan konseling. Jurnal Kajian Bimbingan dan Konseling, 4(2), 75-80.

Syed, M. (2015). Emerging adulthood. (J. J. Arnett, Ed.) (Vol. 1). Oxford University Press. https://doi.org/10.1093/ oxfordhb/9780199795574.013.9

Travis, J. W., \& Ryan, R. S. (2004). Wellness workbook: How to achieve enduring health and vitality. Random House Digital, Inc.

Triaswari, P., \& Utami, M. S. (2014). Kesejahteraan psikologis mahasiswa ditinjau dari stres. Skripsi. Yogyakarta: Universitas Gadjah Mada.

Udhayakumar, P., \& Illango, P. (2018). Psychological well-being among college students. Journal of Social Work Education and Practice, 3(2), 79-89.

Wardati \& Jauhar, M. (2011). Implementasi bimbingan dan konseling di sekolah. Jakarta: Prestasi Pustakaraya.

Worthington, E. L., Wade, N. G., Hight, T. L., Ripley, J. S., McCullough, M. E., Berry, J. W., ... O’Connor, L. (2003). The Religious Commitment Inventory--10: Development, refinement, and validation of a brief scale for research and counseling. Journal of Counseling Psychology, 50(1), 84-96. https://doi.org/10.1037/00220167.50.1.84

Yasin, A. S., \& Dzulkifli, M. A. (2010). The relationship between social support and psychological problems among students. International Journal of Business and Social Science, 1(3), 110-116.

Zimet, G. D., Dahlem, N. W., Zimet, S. G., \& Farley, G. K. (1988). The multidimensional scale of perceived social support. Journal of Personality Assessment, 52(1), 30-41. https://doi.org/10.1207/s15327752jpa5201_2 